\title{
El descubrimiento de Dostoievski por parte de Nietzschel
}

\author{
Nietzsche's discovery of Dostoievsky's work \\ PAOLO STELLINO \\ Universitat de Valencia
}

Recibido: 17-04-2007 Aprobado definitivamente: 08-10-2007

RESUMEN

En las siguientes páginas se intentará recorrer los pasos a través de los cuales Nietzsche entró en contacto con la obra dostoievskiana y delinear las posiciones principales de la crítica acerca de la problemática, muy discutida, de qué obras de Dostoievski fueron leídas por Nietzsche. Para ello, nos basaremos en el análisis de las obras, de los fragmentos póstumos y de las cartas del último periodo de la vida consciente de Nietzsche.

\section{PALABRAS CLAVES}

NIETZSCHE, DOSTOIEVSKI, DESCUBRIMIENTO

\begin{abstract}
In the following pages we attempt to reconstruct Nietzsche's discovery of Dostoevsky's work. Afterwards we will focus on critical studies in order to specify how the philosopher got to know the Russian author's novels and specifically which books he may have read. We will base our investigation on Nietzsche's work, notes and letters.
\end{abstract}

KEYWORDS

NIETZSCHE, DOSTOEVSKY, DISCOVERY

1 Este artículo se inserta en el Programa F.P.U. del Ministerio de Educación y Ciencia (Ref. Becario: AP2005-5368) y en el Proyecto de Investigación Científica GV06/145, financiado por la Conselleria d'Empresa, Universitat i Ciencia de la Generalitat Valenciana.

(C) Contrastes. Revista Internacional de Filosofía, vol. XIII (2008), pp. 79-99. ISSN: 1136-4076

Licenciatura de Filosofía, Universidad de Málaga, Facultad de Filosofía y Letras

Campus de Teatinos, E-29071 Málaga (España) 


\section{UN ENCUENTRO CASUAL}

La primera alusión de Nietzsche a Dostoievski se puede encontrar en una carta de 12 de febrero de 1887, que el filósofo envía desde Niza a su amigo Franz Overbeck, preguntándole al final de la misma si ya le había escrito acerca del escritor ruso:

¿Te he escrito de H. Taine? ¿Y de que me encuentra infiniment suggestif [infinitamente sugestivo]? ¿Y de Dostoievski? ${ }^{2}$

Un día después, Nietzsche escribe a Peter Gast, comparando a Dostoievski con Stendhal, por el placer que le produce el leerlo, y lo define como un psicólogo, definición que el filósofo volverá a repetir en el Crepúsculo de los ídolos ${ }^{3}$ y en un fragmento póstumo de principios de $1888:^{4}$

¿Conoce a Dostoievski? Excepto Stendhal, nadie me ha causado tanto placer y sorpresa: un psicólogo, con el que yo me entiendo. ${ }^{5}$

Estas breves y fugaces alusiones son completadas por una descripción más detallada de su primer contacto con el escritor ruso, que Nietzsche nos ofrece en una carta de 23 de febrero de 1887 dirigida a Overbeck:

De Dostoievski yo no conocía ni el nombre hasta hace pocas semanas -iyo un hombre inculto que no lee «periódicos»! Un zarpazo casual (zufälliger Griff) en una tienda de libros me puso ante los ojos su obra L'esprit souterrain, recién traducida al francés (jalgo igual de casual me ocurrió con Schopenhauer cuando yo tenía veintiún años, y con Stendhal cuando tenía treinta y cinco!) El instinto de afinidad (Verwandschaft) (¡o qué nombre le daré?) dejó oír su voz enseguida, mi alegría fue extraordinaria: tengo que retrotraerme a mi conocimiento de Rouge et Noir de Stendhal para recordar una alegría igual. (Son dos relatos, el primero, propiamente una pieza de música, de una música muy extraña, muy poco alemana; el segundo,

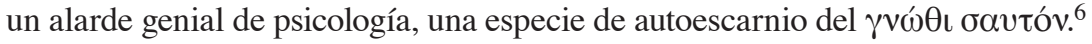

2 F. Nietzsche, Briefwechsel. Kritische Gesamtausgabe, III, 5, G. Colli y M. Montinari (eds.). Berlin-New York: W. de Gruyter, 1984, p. 21. Tanto en este caso, como en los siguientes, la falta del nombre del traductor indica que la traducción ha sido efectuada por el autor del presente artículo.

3 Cf. F. Nietzsche, Crepúsculo de los ídolos, «Incursiones de un intempestivo», 45.

4 Cf. F. Nietzsche, Fragmentos póstumos (1885-1889), primavera de 1888, 15 [9], tr.

J. L. Vermal y J. B. Llinares. Madrid: Tecnos, 2006, p. 626.

5 F. Nietzsche, Briefwechsel, III, 5, op. cit., p. 24.

$6 \quad$ Ibid., p. 27. 
Con esta carta Nietzsche parece colocar temporalmente -por cuanto de una forma muy vaga e imprecisa («hasta hace pocas semanas»)- y espacialmente - una tienda de libros de Niza- su descubrimiento de Dostoievski, que, como el mismo filósofo reconoce, se parece mucho al encuentro, en un anticuario de Leipzig en 1867, del libro schopenhaueriano El mundo como voluntad y representación. La obra de Dostoievski, junto a la de Schopenhauer y de Stendhal (Rojo y negro), despierta la alegría del filósofo y suscita en él un instinto de afinidad o, mejor dicho, de parentesco.

La obra, a la que Nietzsche se refiere en esta carta a Overbeck, es el volumen titulado L'esprit souterrain, ${ }^{7}$ compuesto por dos partes distintas: una versión abreviada de las dos partes de Memorias del subsuelo (Zapiski iz podpol'ja $a^{8}$ titulada «Lisa» (segunda parte) con un prefacio constituido por la traducción completa de La posadera (Hozjajka), titulada «Katia» (primera parte). Estas dos partes son presentadas por un narrador anónimo como relatos diferentes de las veleidades amorosas del protagonista de La posadera, Ordinov, y unidas entre ellas a través de una exposición modelada sobre el ejemplo de la introducción dostoievskiana de Memorias de una casa muerta (Zapiski is mertvogo doma). Según refiere C. A. Miller en su ensayo Nietzsche's «Discovery» of Dostoie$v s k i$, si la traducción de La posadera es bastante fiel al texto ruso original, al contrario, la tentativa de adaptar Memorias del subsuelo como continuación de la primera parte titulada «Katia», habría causado interpolaciones frecuentes y repetidas del texto dostoievskiano e incluso la introducción de fragmentos ficticios referidos a La posadera. ${ }^{9}$

Es indudable que el volumen L'esprit souterrain le gusta mucho a Nietzsche, que elogia la primera parte como una pieza musical muy poco alemana (sehr undeutscher Musik) y la segunda como un golpe de genialidad (Geniestreich) de Psicología, volviendo a repetir estas definiciones en otra carta a Gast de 7 de marzo de 1887:

Lo primero que he conocido de él, que acaba de aparecer en traducción francesa, se llama L'esprit souterrain, que contiene dos relatos: el primero, una especie de música desconocida; el segundo, un verdadero alarde genial de psicología -un terrible y

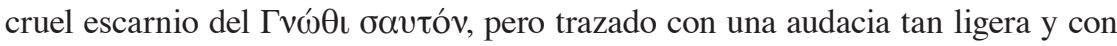
tanto deleite de fuerza superior, que yo quedé totalmente ebrio de contento. ${ }^{10}$

7 Cf. F. Dostoïevski, L'esprit souterrain, tr. Halpérine-Kaminsky y Ch. Morice. Paris : Plon-Nourrit, 1884.

8 Tanto en el presente caso, como en los siguientes, la transliteración de la grafía rusa a la grafía latina ha sido efectuada conforme a la tabla de transliteración del ruso de la UNESCO.

9 Cf. C. A. Miller, «Nietzsche's "Discovery" of Dostoevsky», Nietzsche Studien. Internationales Jahrbuch für die Nietzsche Forschung, II (1973), p. 207.

10 F. Nietzsche, Briefwechsel, III, 5, op. cit., p. 41. 
En la misma carta, Nietzsche retoma el paralelo con Stendhal, ya presente en la carta de 23 de febrero enviada a Overbeck, y vuelve a repetir dos datos muy importantes: por una parte, el contacto con Dostoievski ha sido meramente casual, ergo Nietzsche hasta hace pocas semanas no conocía ni el nombre del escritor ruso; por otra parte, el filósofo alemán intuye desde el primer momento que Dostoeivski es un alma muy afín a él, que su pensamiento está estrechamente relacionado con el suyo, y hasta advierte un sentimiento de afinidad y de parentesco:

Con Dostoievski me ha ocurrido lo mismo que anteriormente con Stendhal: el contacto más casual, un libro que se abre en una librería, desconocimiento incluso del nombre $-\mathrm{y}$ el instinto que repentinamente dice que aquí he tropezado con alguien afín. ${ }^{11}$

Si creemos a las palabras de Nietzsche, el encuentro con el escritor ruso ha sido absolutamente fortuito: que fuese un contacto (Berührung) o un zarpazo (Griff), lo que más nos interesa es el carácter casual (zufällig) de dicho encuentro.

Como ha destacado justamente Miller, la fórmula «Unbekanntschaft bis $a u f^{12}$ den Namen» no deja de ser semánticamente bastante ambigua, por la posibilidad de interpretar bis auf como «desconocimiento más allá (beyond) del nombre» o, como se traduce normalmente, «desconocimiento incluso o hasta (even) del nombre». ${ }^{13}$ En realidad, la carta de 23 de febrero a Overbeck nos ayuda a resolver y esclarecer esta ambigüedad, puesto que Nietzsche escribe al amigo que hasta hace pocas semanas de Dostoievski no conocía ni el nombre.

La afirmación nietzscheana del desconocimiento -incluso del nombre- de Dostoievski no deja, de todos modos, de asombrar, si se consideran dos factores muy importantes. En primer lugar, a partir de la traducción de 1882 de W. Henkel de Crimen y castigo (Prestuplenie i nakazanie), la reputación del escritor ruso y de algunas obras suyas tuvo una gran resonancia en Alemania y, en este sentido, es raro que hasta inicios de 1887 el nombre de Dostoievski pasara desapercibido para el filósofo alemán. Por otra parte, no cabe duda de que la vida de Nietzsche, ya a partir de 1879, año en que dejó su profesorado en la Universidad de Basilea, fue una vida de soledad completa y de aislamiento del mundo, el cual quedaba fuera de su habitación, una vida angustiada por «la pena que comporta cada privación larga de luz y de aire». ${ }^{14}$ Las palabras de

11 Ibid.

12 La cursiva es nuestra.

13 Cf. C. A. Miller, op. cit., p. 205.

14 F. Nietzsche, Aurora, «Prólogo», 1, tr. G. Dieterich. Barcelona: Alba, 1999, p. 11. 
W. Ross, biógrafo de Nietzsche, acerca de los últimos nueve años y medio de lucidez de Nietzsche son, en este sentido, muy significativas:

Su vida ya no es más que el sostén de su obra, condición precaria pero sustancial para el proceso creador. De ella nacen los textos que conforman al Nietzsche filósofo. La enfermedad se ha convertido en su compañera inseparable; los innumerables cambios de domicilio son una herramienta en la búsqueda del clima más adecuado para su trabajo. Las relaciones humanas se diluyen o se rompen: la soledad, en tantas ocasiones deploradas, es condición sine qua non para hacerse con toda la concentración creadora. La odia y, al mismo tiempo, la necesita. ${ }^{15}$

Aunque fuese lector asiduo, cabe, de todos modos, la posibilidad de que Nietzsche, «hombre inculto que no lee "periódicos"», ${ }^{16}$ recluso en la soledad y en el aislamiento de su cuarto, no hubiese tenido noticia de Dostoievski hasta el fortuito encuentro de L'esprit souterrain en una librería de Niza. Pero aún más asombrosa parece la distracción del filósofo alemán a la hora de leer la recensión de septiembre de 1886 de Más allá del bien y del mal en la revista suiza Bund ${ }^{17}$ escrita por J. V. Widmann, donde la obra nietzscheana es criticada duramente por la peligrosidad de las ideas expresadas. El crítico pone como epígrafe de su artículo el siguiente pasaje de El adolescente (Podroctok) de Dostoievski, indicando implícitamente el cinismo de Lambert, personaje de la misma obra, como el resultado inexorable del perspectivismo del filósofo alemán:

Permítanme: he tenido como camarada a un cierto Lambert que me decía ya a los dieciséis años que, cuando fuera rico, su mayor placer consistiría en alimentar a perros con pan y carne cuando los hijos de los pobres estuvieran muriéndose de hambre y que, cuando no tuvieran con qué calentarse, él compraría todo un pedazo de bosque, lo transportaría al campo abierto y caldearía el aire, sin dar a los pobres ni una sola ramita. ¡He ahí los sentimientos que él tenía! Pues bien, díganme ustedes qué podré responder a ese canalla pura-sangre si me pregunta: «¿Por qué hace falta en forma alguna ser virtuoso?». 18

Como testimonia la carta de 12 de octubre de 1886 de Nietzsche a Overbeck, el filósofo leyó la recensión de Widmann que, por cierto, le causó la preocupación de que la posibilidad de que cada tipo de policía se interesara prematuramente

15 W. Ross, Friedrich Nietzsche. El águila angustiada. Una biografía, tr. R. Hervás. Barcelona-Buenos Aires: Paidós, 1994, p. 577.

16 F. Nietzsche, Briefwechsel, III, 5, op. cit., p. 27.

17 Cf. J. V. Widmann, «Nietzsches gefährliches Buch», Bund, XXXVII $(16 / 17.09 .1886)$.

18 F. Dostoyevski, El adolescente, tr. M. Orta Manzano. Barcelona: Juventud, 2001, p. 64. 
por su obra. Pero por cuanto pueda parecer asombroso y extraño, el filósofo no se fijó en el paso de El adolescente o, a lo mejor, la cita dostoievskiana no suscitó su curiosidad, perdiendo así la ocasión de descubrir, con un poco de antelación, el atractivo que la obra del escritor ruso estaba destinada a ejercer sobre él. Fue su amigo Heinrich Köselitz quien, en una carta de 18 de marzo de 1887, llamó la atención del filósofo sobre el hecho de que el epígrafe del artículo de Widmann provenía de la obra dostoievskiana El adolescente. ${ }^{19}$

En realidad, se podría dudar de la exactitud de la expresión nietzscheana - «hasta hace pocas semanas»- de la carta de 23 de febrero dirigida a Overbeck, si se piensa en la referencia directa al subterráneo contenida en el «Prólogo» a la nueva edición de Aurora, en el que Nietzsche trabajó en el mes de octubre de 1886 en Ruta Ligure. ${ }^{20}$ Esta referencia, por su afinidad y semejanza con el subsuelo dostoievskiano, parece indicarnos que la lectura de L'esprit souterrain por parte del filósofo podría remontarse, por lo menos, a cuatro meses antes de la mencionada carta a Overbeck.

En el «Prólogo» mencionado, el filósofo prepara al lector de su libro al encuentro con un subterráneo en acción, que excava hacia la profundidad y quiere la oscuridad porque sabe que, después de tanta fatiga, volverá a tener su propia aurora. Pero antes de llegar al nuevo amanecer, se ha de descender hasta el fondo de ese suelo, sobre el cual los filósofos han construido durante largo tiempo sus edificios inestables, a pesar de que ellos se vinieran abajo: el suelo de la moral, «la verdadera Circe de los filósofos». ${ }^{21}$ El difícil camino, que Nietzsche ha escogido, ha sido el de socavar la confianza del ser humano en la moral y, para hacer eso, ha tenido que convertirse en un aparente Trofonio:

En este libro se encontrará a un «subterráneo» en acción, un perforador, un cavador, un socavador. Se le ve, presuponiendo que se tengan ojos para este trabajo de profundidad, -cómo avanza lenta, serenamente, con suave determinación, sin que se manifieste demasiado la dificultad que toda prolongada falta de luz y aire trae consigo; podría, incluso, considerársele satisfecho en su oscuro trabajo. ¿Acaso no parece que le guía cierta fe, que le compensa un consuelo? ¿Que quizá desee su propia y prolongada oscuridad, su inexplicabilidad, su secreto, su enigma, porque sabe lo que también tendrá: su propio amanecer, su propia liberación, su propia aurora?... Sin duda, volverá: no le preguntéis que busca ahí abajo, ya os lo dirá él mismo, este aparente Trofonio y subterráneo, cuando se haya «hecho hombre»

19 F. Nietzsche, Briefwechsel, III, 6, op. cit., p. 35-36.

20 Cf. G. Colli y M. Montinari, Chronik zu Nietzsches Leben, en F. Nietzsche, Kritische Studienausgabe, XV, op. cit., p. 162.

21 F. Nietzsche, Aurora, «Prólogo», 3, op. cit., p. 13. 
de nuevo. Se desaprende a fondo a callar cuando se ha sido durante tanto tiempo topo y se ha estado solo, como él. ${ }^{22}$

Leyendo los párrafos del «Prólogo» de Aurora y confrontándolos con los Apuntes del subsuelo, podemos encontrar, por lo menos, tres analogías patentes entre los dos textos. En primer lugar, el término nietzscheano subterráneo (unterirdisch) es idéntico al vocablo dostoievskiano subsuelo (podpol'e), no sólo semánticamente, sino también en la utilización que de él hacen los dos autores. El narrador ficticio de los Apuntes, que sobrevive en un rincón, en un «agujero subterráneo, maloliente y asqueroso ( $v$ svoem merzkom, vonjučem podpol'e)», ${ }^{23}$ cultivando «sueños subterráneos (v mečtah [...] podpol'nyh)» ${ }^{24} \mathrm{y}$ anhelando la tranquilidad como un ratón infeliz que ha decidido «enterrarse en vida en el subsuelo ( $v$ podpol'e)», ${ }^{25}$ no es figurativamente muy distinto del Trofonio nietzscheano que excava en profundidad, avanzando lentamente, pero con determinación y sin ningún tipo de miedo a la falta de luz y de aire, que su tarea trae consigo. En realidad, es muy justificable la sospecha de que el mismo Nietzsche hubiese sido influenciado por la lectura del texto dostoievskiano a la hora de escribir estas páginas y no podemos pasar por alto la increíble semejanza entre el hombre del subsuelo del autor ruso y el «subterráneo» en acción del filósofo alemán.

En segundo lugar, la locuacidad de Nietzsche, que él mismo atribuye a Trofonio, su álter ego, en las últimas líneas del párrafo ya mencionado -«no le preguntéis qué busca ahí abajo, ya os lo dirá él mismo» ${ }^{26} \mathrm{y}$ «se desaprende a fondo a callar cuando se ha sido durante tanto tiempo topo y se ha estado solo, como él» ${ }^{27}$-, parece estar inspirada en el siguiente paso de la primera parte de los Apuntes, que refleja el deseo insistente de hablar por parte del protagonista:

Sin embargo, ¿saben ustedes una cosa? Estoy convencido de que a individuos como yo, que viven en el subsuelo, hay que tenerlos muy a raya. Aunque pueden pasar cuarenta años en un sótano oscuro sin decir esta boca es mía, tan pronto como salen a la luz se sueltan la lengua y no paran de hablar, hablar y hablar... ${ }^{28}$

22 Ibid., 1, p. 11.

23 F. M. Dostoyevski, Apuntes del subsuelo, tr. J. López-Morillas. Madrid: Alianza, 2005, p. 25.

24 Ibid., p. 143.

25 Ibid., p. 26.

26 F. Nietzsche, Aurora, «Prólogo», 1, op. cit., p. 11.

27 Ibid.

28 F. M. Dostoyevski, Apuntes del subsuelo, op. cit., p. 51. 
En tercer lugar, hablando de la confianza de los filósofos en la moral en el segundo párrafo del «Prólogo», Nietzsche dirige a sus lectores la siguiente pregunta - «pero ¿no me entendéis?» ${ }^{29}$-, que, en realidad, se parece mucho a la del narrador ficticio dostoievskiano: « ¿Ustedes, señores, no lo comprenden todavía?».30

Más allá de las analogías que se pueden encontrar entre el «Prólogo» de Aurora y los Apuntes del subsuelo, hay que considerar una posible alusión a Dostoievski, presente en el aforismo 347 de La gaya ciencia, que podría confirmar una lectura de la novela dostoievskiana por parte de Nietzsche antes de 1887. Dicho aforismo forma parte del libro quinto, añadido al texto originario en la segunda edición de la obra, al que el filósofo trabajó a partir de octubre de 1886, hasta diciembre del mismo año. ${ }^{31}$ Aquí Nietzsche, atribuyendo la necesidad de creer en una fe -religiosa, metafísica, positivista, etc.- a la debilidad de la voluntad, se refiere a las alternativas miserandas que muchos contemporáneos suyos buscan, para apagar el deseo de certidumbre al que anhelan, y cuenta entre ellas «la patriotería (llamo así a lo que en Francia se denomina chauvinisme y en Alemania, "alemán")», los «credos estéticos, tales como el naturalisme parisiense» y «el nihilismo al modo de San Petersburgo (es decir, el credo de descreimiento, hasta el extremo del martirio en aras de dicho credo)».32

En el nihilismo a la manera de Petersburgo (Nihilismus nach Petersburger Muster) podría verse legítimamente una alusión a Dostoievski, aunque la fe en la incredulidad llevada hasta el martirio parece ser una característica más apropiada a la tentativa de emancipación de la creencia en Dios por parte de Kirillov, que al rechazo de la realidad por parte del hombre del subsuelo. Por otra parte, se ha de excluir la posibilidad de que Nietzsche se refiriera en este pasaje a Kirillov, personaje de Los demonios, ya que es muy probable que el filósofo no llegara a leer esta novela antes del otoño de $1887 .{ }^{33}$

En el mencionado aforismo de La gaya ciencia, Nietzsche podría referirse más bien al autor ruso Iván Turgenev, que transcurrió parte de su vida en Petersburgo. Turgenev escribió en 1862 la novela Padres e hijos (Otcy i deti), difundiendo en el contexto intelectual europeo el término 'nihilismo' (nigilizm), atribuido al joven Bazarov, protagonista de la novela. El filósofo alemán, que ya

29 F. Nietzsche, Aurora, «Prólogo», 2, op. cit., p. 12.

30 F. M. Dostoyevski, Apuntes del subsuelo, op. cit., p. 30.

31 El «Prólogo», también añadido en ocasión de la segunda edición, lleva la fecha de otoño de 1886. Fue escrito por Nietzsche en Ruta, cerca de Génova, así como el «Prólogo» de la nueva edición de Aurora.

32 F. Nietzsche, La gaya ciencia, V, 347, en F. Nietzsche, Obras completas, III, trad. P. Simon. Buenos Aires: Prestigio, 1970, p. 234.

33 Los fragmentos de Los demonios que Nietzsche transcribió en sus apuntes son del período comprendido entre noviembre de 1887 y marzo de 1888. 
había leído esta obra en 1873, durante su estancia en Basilea como profesor de filología, podría haber pensado en él, a la hora de desenmascarar una cierta forma de nihilismo como un producto más de la ansia vehemente de certeza,${ }^{34}$ pero, en realidad, la alusión nietzscheana queda bastante ambigua y, por el momento, nos es imposible determinar con exactitud a quien se refería el filósofo con la mencionada expresión del «nihilismo a la manera de Petersburgo».

Lo que más asombra, es que en el aforismo 208 de Más allá del bien y del mal -texto que se acabó de imprimir a finales de julio de $1886,{ }^{35}$ es decir, unos meses antes de que Nietzsche se pusiese a trabajar en los ya mencionados «Prólogo» de Aurora y en el quinto libro de La gaya ciencia- es posible encontrar una alusión increíblemente similar a la del «nihilismo a la manera de Petersburgo»:

Cuando un filósofo da a entender hoy que él no es un escéptico, -yo espero que se haya percibido eso en la descripción que acabo de hacer del espíritu objetivo -todo el mundo oye eso con disgusto; se lo examina con cierto recelo, se querría preguntarle y preguntarle muchas cosas..., incluso, entre los oyentes medrosos, que ahora existen en gran cantidad, se le califica, desde ese momento, de peligroso. Les parece como si, en el repudio del escepticismo por parte de aquél, ellos escuchasen desde lejos un ruido malvado y amenazador, como si en alguna parte se estuviera ensayando una nueva sustancia explosiva, una dinamita del espíritu, quizá una nihilina rusa recién descubierta ${ }^{36}$ (ein neuentdecktes Russisches Nihilin), un pesimismo bonae voluntatis [de buena voluntad] que no se limita a decir no, a querer no, sino -jcosa horrible de pensar!- a hacer no. ${ }^{37}$

En la adecuada interpretación del adjetivo neuentdecktes, referido a la nihilina rusa, ${ }^{38}$ podría solucionarse, tal vez, el problema del momento exacto, en que Nietzsche descubrió a Dostoievski. Si ese adjetivo fuese referido a sí mismo, es decir, si fuese él mismo el que hubiera descubierto recientemente la nihilina rusa, entonces, se podría interpretar este paso como una clara alusión a Dostoievski, ya que, como hemos mencionado, la lectura de la obra de Turgenev Padres e hijos, por parte del filósofo alemán, remonta al año 1873, es decir, hacía ya trece años que Nietzsche había leído dicha novela y no hubiera tenido sentido, que en 1886 utilizase el término neuentdecktes para referirse al propio

34 Cf. F. Nietzsche, La gaya ciencia, V, 347, op. cit., p. 234.

35 Cf. G. Colli y M. Montinari, Chronik zu Nietzsches Leben, op. cit., p. 159.

36 La cursiva es nuestra.

37 F. Nietzsche, Más allá del bien y del mal, «Nosotros los doctos», VI, 208. Madrid: Alianza, 2003, p. 158.

38 Por «nihilina» ha de entenderse metafóricamente una sustanciaque, como un veneno, envenena el organismo de la sociedad europea, diseminándose en ella. 
descubrimiento de Turgenev. Al contrario, si el adjetivo no fuese referido a sí mismo, sino, como es muy probable, al público literario europeo de la época, entonces, sería lícito ver, en este pasaje, una referencia a la obra turgeneviana, que -dada su publicación en 1862- podía aún definirse como una obra recién descubierta.

La ambiguiedad de esta alusión a la nihilina rusa permanece indudable y el problema es de difícil resolución. Por el momento, preferimos limitarnos a comprobar con asombro que estudiosos como C. A. Miller y G. Pacini, que se han ocupado del problema del momento exacto en el que Nietzsche descubrió a Dostoievski, se hayan olvidado o hayan omitido la mencionada referencia a la nihilina rusa recién descubierta, referencia que, desde nuestra perspectiva, podría ser reveladora a la hora de enfrentarse a ese problema.

\section{NiETZSCHe LeCTOR DE Dostoievski}

A la hora de establecer cuáles de las obras dostoievskianas el filósofo alemán leyó, nos encontramos con dos dificultades principales: en primer lugar, aunque pueda parecer raro y asombroso, Nietzsche en Ecce Homo -su autobiografía intelectual escrita en el otoño de 1888, es decir, más de un año y medio después del descubrimiento de la obra del escritor ruso- no cita a Dostoievski entre los autores que más le han servido de inspiración. En este sentido, la falta del nombre del escritor ruso junto a Stendhal, Shakespeare y Heine, parece inexplicable, considerando que, en la carta a Gast de 13 de febrero de 1887, el mismo Nietzsche escribe, con referencia a Dostoievski: «Excepto Stendhal, nadie me ha causado tanto placer y sorpresa». ${ }^{39} \mathrm{Ch}$. Andler, en su estudio Nietzsche et Dostoievsky escribe: «¿Creeremos en una omisión casual? ¿En un descuido? Al contrario, ¿no es ya una desilusión? ¿No se ha dado cuenta ya Nietzsche, de que Dostoievski no pertenece a su raza y que, decadente y cristiano, no puede compartir sus esperanzas?». ${ }^{40}$ La interpretación de Andler estimula a pensar de nuevo la relación entre los dos pensadores, pero a pesar de que se juzgue esta omisión del nombre del escritor ruso como un descuido casual o, más bien, como una falta significativa, nos encontramos en Ecce Homo frente a un silencio, que de ninguna manera nos ayuda a comprender hasta donde llegó exactamente el conocimiento de Nietzsche de las obras dostoievskianas.

En segundo lugar, hay que considerar que en la biblioteca nietzscheana no ha sido encontrada ninguna obra de Dostoievski -dificultad, sin duda alguna,

39 F. Nietzsche, Briefwechsel, III, 5, op. cit., p. 24.

40 Ch. Andler, «Nietzsche et Dostoievski», en AA. VV., Mélanges d'histoire littéraire générale et comparée offerts à Fernand Baldensperger, I. Genève : Slatkine, 1972, p. 1. 
aún mayor que la precedente-aunque, por lo menos, podemos saber afortunadamente con precisión y exactitud, a través del análisis de las cartas nietzscheanas y de los fragmentos póstumos, cuáles fueron las obras de Dostoievski que el filósofo alemán leyó. Al contrario, por lo que atañe a las obras del escritor ruso no mencionadas por Nietzsche, la tarea del intérprete es mucho más ardua y complicada.

Como ya hemos visto, Nietzsche cita explícitamente el volumen L'esprit souterrain en las cartas de 23 de febrero a Overbeck y de 7 de marzo a Gast. De estas dos citas se puede derivar la información de que el filósofo alemán leyó tanto La posadera, primera parte de dicho volumen, como Memorias del subsuelo, segunda parte.

En la ya mencionada carta de 7 de marzo, Nietzsche, explicando a Gast la complicada evolución espiritual de Dostoievski, nos ofrece una aclaración más:

Hasta ahora es poco lo que sé de su posición, su fama, su historia: murió en 1881. En su juventud le fue mal: enfermedad, pobreza, pese a su ascendencia aristocrática; a los veintisiete años condenado a muerte, indultado en el cadalso, luego cuatro años en Siberia, encadenado, en medio de autores de graves crímenes. Este tiempo fue decisivo: descubrió la fuerza de su intuición psicológica, es más, su corazón se endulzó y se profundizó con ello -su libro de recuerdos de ese tiempo, La maison des morts, es uno de los "libros más humanos" que hay. Lo primero que he conocido de él, que acaba de aparecer en traducción francesa, se llama L'esprit souterrain [...]. Entretanto, por recomendación de Overbeck, a quien pregunté en mi última carta, he leído además Humilés et offensés (lo único que Overbeck conocía), con el máximo respeto por el artista Dostoievski. ${ }^{41}$

Este paso de la carta a Gast, nos informa, no sólo que el filósofo leyó Memorias de una casa muerta y Humillados y ofendidos (Unižennye i oskorblennye) -que tuvo que gustarle mucho y suscitar en él «el máximo respeto por el artista Dostoievski» ${ }^{42}-$, sino que esta obra, como en el caso de La posadera y Memorias del subsuelo, fue leída en la traducción francesa por Nietzsche, cosa que podría resultar extraña, si se piensa que en ese momento la traducción alemana estaba disponible, pero que se justifica con el simple hecho de que el filósofo, en ese momento, se encontraba en Niza y que, de todos modos, conocía bastante bien el idioma francés.

En realidad, la lectura de las obras dostoievskianas en francés por parte de Nietzsche puede ser, no tanto el resultado de una casualidad, sino, más bien,

41 F. Nietzsche, Briefwechsel, III, 5, op. cit., pp. $41 \mathrm{~s}$.

42 Ibid. 
la consecuencia de una voluntaria elección. En este sentido, en una postal de 27 de marzo de 1887, Nietzsche revela a Gast que «los franceses traducen más finamente (delikater) que el tremendo judío Goldschmidt (con su ritmo de la sinagoga)».43

El Goldschmidt, al que el filósofo se refiere, es el traductor del volumen Erzählungen von F. M. Dostojevskij, ${ }^{44}$ que Gast había enviado a Nietzsche. El filósofo le agradece la expedición con una postal -«iperdón!, si le doy las gracias por su carta y por la traducción de Dostoievski, que acaba de llegar, únicamente con una tarjetita ${ }^{45}-$ y envía al amigo a su vez Humiliés et offensés.

Como refiere W. Gesemann en su estudio Nietzsches Verhältnis zu Dostoevskij auf dem europäischen Hintergrund der 80er Jahre, ${ }^{46}$ el volumen enviado a Nietzsche por parte de Gast, comprendía los siguientes relatos dostoievskianos: Die Wirtin (La posadera, Hozjajka), Christbaum und Hochzeit (Navidad y boda, Elka i cvad'ba), Helle Nächte (Noches blancas, Belye noči) y Der ehrliche Dieb (El ladrón honrado, Čestnyj vor). ${ }^{47}$ Se puede suponer razonablemente que Nietzsche leyera por lo menos algunos de estos cuentos, para poder luego criticar el estilo de la traducción de Goldschmidt.

Nietzsche, como él mismo revela en la carta a su amiga Malwida von Meysenbug de 12 de mayo de 1887, sigue sintiéndose siempre más afín (verwandt) a los franceses y a los rusos -el filósofo vuelve aquí a hablar del mismo instinto de afinidad o parentesco (Instinkt der Verwandtschaft) de la carta de 23 de febrero a Overbeck-, y siempre menos a los campesinos instruidos alemanes, y se declara extasiado por Dostoievski, dando prueba que el atractivo ejercido por el escritor ruso sobre él, no sólo no ha disminuido, sino que más bien ha aumentado y se ha consolidado:

Ir a Versailles - jay, si sólo me fuera posible! Ya que adoro el círculo de hombres, con el que Usted se encuentra (confesión insólita para un alemán: pero en la Europa actual me siento afín sólo a los espiritualísimos franceses y rusos, y de ninguna manera a los campesinos instruidos de mi tierra, que juzgan todo según el principio "Deutschland, Deutschland über Alles"). [...] En Zurich he visitado a

43 Ibid., p. 50

44 F. M. Dostojevskij, Erzählungen von F. M. Dostojevskij, tr. W. Goldschmidt. Leipzig: Reclams Universal-Bibliothek, 1886.

45 F. Nietzsche, Briefwechsel, III, 5, op. cit., p. 50.

46 W. Gesemann, «Nietzsches Verhältnis zu Dostoevskij auf dem europäischen Hintergrund der 80er Jahre», Die Welt der Slaven, VI, 2, (Juli 1961).

47 El quinto relato de este volumen tiene, en la traducción alemana, el titúlo de Weihnacht y, hasta el momento, por la imposibilidad de encontrar el texto original y hacer una comparación, no nos ha sido posible identificar dicho relato. De todos modos, sería razonable suponer que se trate del cuento El árbol de navidad (Mal'čiku na elke). 
la excelente señorita von Schirnhoffer, que volvía en ese momento de Paris, dudosa acerca de su futuro, su intención y su perspectiva, pero, igual que yo, extasiada por Dostoievski. ${ }^{48}$

En el mismo mes de mayo, Overbeck envía al amigo filósofo un escrito de Karl Bleibtreu, redactor del Magazin für die Literatur des In- und Auslandes en los años 1886-88. Nietzsche lee el escrito y contesta indignado al amigo con una carta de 13 de mayo desde Chur:

Por último, te devuelvo el [escrito de] "Bleibtreu", al que no quiero ser fiel (treu bleiben $)^{49}$ un instante más: no puedo de ninguna manera deducir, que sus pretensiones estén basadas sobre cualidades verdaderas [...]. ¡Byron y Scott en la Alemania actual! ¡Junto a eso la admiración tolerable hacia Zola! Y ¡que pobreza psicológica, por ejemplo en el rechazo tajante, con el que reflexiona sobre la última obra de D[ostoievski]! (Justamente el hecho de que la más alta microscopia y perspicacia (Feinsichtigkeit) psicológica no añaden nada al valor de una persona, es el problema que más le interesa a D[ostoievski]: ¡tal vez porque lo ha experimentado desde cerca en las relaciones rusas! (Entre otras cosas, al respecto aconsejo la breve obra de D[ostoievski] L'esprit souterrain, de recién traducida al francés, cuya segunda parte explica, de una manera tan valiente, esa paradoja muy real). ${ }^{50}$

Según la opinión de Gesemann, ${ }^{51}$ en la referencia a la última obra de Dostoievski por parte de Nietzsche habría de entenderse, por dos razones fundamentales, Crimen y castigo: en primer lugar, la última obra que Dostoievski escribió fue Los hermanos Karamazov (Brat'ja Karamazoby), elaborada en los años 1878-80. Dicha obra fue traducida al francés sólo en $1888,{ }^{52} \mathrm{y}$, en el momento en que Nietzsche escribía a Overbeck (13 de mayo de 1887), estaba disponible únicamente en ruso, idioma que el filósofo desconocía. Al contrario, Crimen y castigo, conocida con el nombre de «Raskol'nikov», constituía el éxito literario de ese momento y acababa de ser editada por cuarta vez por parte de la editorial Plon de Paris. ${ }^{53}$ En realidad, con la última obra de Dostoievski podrían ser identificadas también otras dos novelas dostoievskianas -El idiota

48 F. Nietzsche, Briefwechsel, III, 5, op. cit., pp. $70 \mathrm{~s}$.

49 Nietzsche juega con las palabras Bleibtreu, el autor del artículo, y treu bleiben, ser o permanecer fiel.

50 F. Nietzsche, Briefwechsel, III, 5, op. cit., pp. 74 s.

51 Cf. W. Gesemann, op. cit., pp. 135 ss.

52 F. Dostoïevski, Les frères Karamazov, tr. Halpérine-Kaminsky y Ch. Morice. Paris: Plon, 1888.

53 F. Dostoïevski, Crime et châtiment, tr. V. Derély. Paris: Plon, 1884. 
(Idiot), publicada en Francia en 1887,,${ }^{54}$ y Los demonios (Besy), en 1886, ${ }^{55}$ ambas editadas por Plon- pero Gesemann, considerando el éxito ya mencionado de Crimen y castigo, parece quedar firme en su afirmación (afirmación que de todos modos puede ser considerada bastante razonable).

En una carta de 4 de julio de 1887 a Hyppolite Taine podría encontrarse, tal vez, la prueba definitiva de que Nietzsche no sólo conocía, sino que también había leído Crimen y castigo. En dicha carta, el filósofo se alegra de encontrar el nombre de Taine en la dedicatoria del último libro del escritor francés Paul Bourget, la novela André Cornélis,${ }^{56}$ libro que, a juicio de Nietzsche, no lograba «hacer, de manera fehaciente, un verdadero agujero fisiológico en el pecho del prójimo», ${ }^{57}$ y que quedaba prisionero en la influencia patente de Dostoievski. ${ }^{58}$ André, el protagonista de la novela de Bourget, es una figura caracterizada sobre el modelo shakespeariano de Hamlet que, después de haber vengado la muerte del padre, tiene que enfrentarse a «angustiosos pensamientos filosófico-psicológicos y justificaciones morales» ${ }^{59}$ que, según el juicio de Gesemann, lo marcarían como una copia inconfundible de Raskolnikow, el protagonista dostoievskiano de Crimen y castigo. En este sentido, siempre según Gesemann, el hecho de que Nietzsche reconociera la influencia de Dostoievski sobre Bourget comprobaría no sólo que el filósofo tenía, por lo menos, noticia de la obra conocida bajo el nombre de «Raskol'nikov», sino que él mismo había leído, con toda probabilidad, dicha novela. ${ }^{60}$

A pesar de que se reconozca o no el hecho de que Nietzsche hubiera leído Crimen y castigo, es indudable, de todos modos, que el filósofo llegase a tener noticia de dicha obra en octubre de 1888 , como se puede comprobar en una carta enviada a Gast desde Turín:

Los franceses han puesto en escena la obra cumbre de Dostoievski. ${ }^{61}$

54 F. Dostoïevski, L'idiot, tr. V. Derély. Paris: Paris, 1887.

55 F. Dostoïevski, Les Possédés, tr. V. Derély. Paris: Plon, 1886.

56 P. Bourget, André Cornélis. Paris: Éditions Larousse, 1887.

57 F. Nietzsche, Briefwechsel, III, 5, op. cit., p. 106.

58 Cf. ibid.: «Pero, ¿parece que el espíritu de Dostoievski nunca dejará en paz a este novelista parisino?». Véase también la carta de Nietzsche a Gast de 7 de marzo de 1887, op. cit., p. 42: «También he notado ya cómo la más reciente generación de novelistas franceses está completamente tiranizada por el influjo de Dostoievski y por los celos con respecto a él (por ejemplo, Paul Bourget)».

59 W. Gesemann, op. cit., p. 138.

60 Ibid.

61 F. Nietzsche, Briefwechsel, III, 5, op. cit., p. 451. 
Según la opinión de Gesemann, Nietzsche aludiría en esta carta a Crimen y castigo, es decir, a aquella novela que en esa época era considerada, como ya hemos visto, el éxito literario y la obra cumbre (Hauptroman) del escritor ruso, novela que había sido puesta en escena a través de una adaptación por parte de P. Ginistry y Hugues Le Roux en el teatro Odéon de Paris a partir de finales de otoño de 1888.

Esta tercera alusión, junto a las otras dos que podemos encontrar en la crítica del escrito de Bleibtreu y de André Cornélis de Paul Bourget, parece apuntar a que Nietzsche, si bien no leyó directamente la obra cumbre de Dostoievski, tuvo, de todos modos, noticia de ella en los últimos meses de su lucidez mental.

Si tratar de comprobar -a través de estas alusiones- una posible lectura por parte de Nietzsche de Crimen y castigo es bastante complicado, por el contrario, menos problemática parece la interpretación de la relación entre la figura del príncipe Myskin de El idiota dostoievskiano y el Jesús nietzscheano de El Anticristo. De la increíble semejanza de algunos rasgos de estas dos figuras, se intuye la gran importancia de comprender si dicha semejanza es el resultado de una lectura e influencia directa de la obra del escritor ruso sobre el filósofo alemán, o si es una prueba más de una afinidad y de un parentesco -la misma Verwandtschaft de la que habla Nietzsche- entre dos espíritus tan similares.

Acerca de este tema, la correspondencia del filósofo con Georg Brandes, estudioso danés y conocedor de la obra dostoievskiana, adquiere una relevancia fundamental. El 6 de octubre de 1888, Brandes escribe a Nietzsche desde Kopenhagen, informándole de que acababa de escribir un nuevo libro -Eindrücke aus Russland-y de que estaba planeando pasar el invierno en Rusia. ${ }^{62}$ Nietzsche contesta el 20 de octubre desde Turín, aludiendo al atractivo que ejercía la literatura rusa sobre él:

¡Ay, qué laborioso es Usted! ¡Y yo idiota, que tampoco comprendo el danés! Creo absolutamente en sus palabras, cuando me dice que en este momento uno se puede «reanimar en Rusia»; considero entre mis más grandes alivios [leer] un libro ruso cualquiera (irgend ein russisches Buch), sobre todo de Dostoievski (iitraducido al francés, no al alemán, por la gracia de Dios!!). ${ }^{63}$

Lo que Nietzsche dice, suscita en seguida la reacción de Brandes que, en una carta de 16 de noviembre de 1888, escribe:

Es increíble cómo lo que Usted ha escrito sobre Dostoievski en su carta o en su libro coincide con mis impresiones sobre él. Le he mencionado también en mi

62 Cf. F. Nietzsche, Briefwechsel, III, 6, op. cit., p. 321.

63 F. Nietzsche, Briefwechsel, III, 5, op. cit., p. 457. 
obra sobre Rusia, donde trato de Dostoievski. Es un gran poeta, pero un tipo repugnante, completamente cristiano y, al mismo tiempo, absolutamente sádico en su vida emotiva. Toda su moral es lo que Usted ha bautizado como moral de esclavos. $^{64}$

Esta intuición de Brandes acerca de Dostoievski y de su moral es confirmada por Nietzsche, que contesta al estudioso danés cuatro día después de que le llegara su carta, es decir, el 20 de noviembre, volviendo a subrayar la perspicacia del escritor ruso como psicólogo: 65

Creo de manera absoluta en sus palabras acerca de Dostoievski; por otra parte, lo considero como el material psicológico más válido que yo conozca, --le estoy increíblemente agradecido, aunque vaya siempre en contra de mis instintos más profundos. ${ }^{66}$

Antes de que Nietzsche se abismara definitivamente en el mundo de las sombras, para citar una expresión del biógrafo nietzscheano W. Ross, ${ }^{67}$ encontramos una última carta de Brandes, dirigida al filósofo y fechada el 23 de noviembre de 1888:

Observe la cara de Dostoievski: ;por un lado una cara rusa de campesino y por otro lado una fisonomía de criminal, nariz chata, pequeños ojos que traspasan y párpados que tiemblan por nerviosismo, una frente muy grande y modelada, que habla de penas innumerables, de una melancolía profundísima, de deseos impuros, de una compasión infinita y de una envidia visceral! Un genio epiléptico, cuya apariencia ya de por sí revela el río de benevolencia que llena su alma, la ola de una sagacidad casi de locos, que se le sube a la cabeza y, por último, la ambición, la enormidad del anhelo y los celos, cuales crea la mezquindad del alma.

Sus héroes no son sólo pobres y miserables, sino también ingenuos de gran finura, prostitutas nobles, con frecuencia en estados alucinatorios, epilépticos con talento, buscadores entusiastas de martirio, justamente los tipos que debemos suponer entre los apóstoles y los discípulos de la primera edad cristiana.

Es indudable que ningún otro espíritu está más lejos del renacimiento. ${ }^{68}$

64 F. Nietzsche, Briefwechsel, III, 6, op. cit., p. 353.

65 Véase al respecto F. Nietzsche, Crepúsculo de los ídolos, «Incursiones de un intempestivo», 45; Fragmentos póstumos (1885-1889), primavera de 1888, 15 [9]; Briefwechsel, III, 5, op. cit., p. 24.

66 F. Nietzsche, Briefwechsel, III, 5, op. cit., p. 483.

67 Cf. W. Ross, op. cit., VI parte, «Descenso al mundo de las sombras».

68 F. Nietzsche, Briefwechsel, III, 6, op. cit., pp. 362 s. 
Leyendo la observación de Brandes acerca de los héroes dostoievskianos, es inevitable pensar enseguida en el pasaje de El caso Wagner, donde Nietzsche, a la hora de describir la contraposición entre la moral de señores (Herren-Moral) y la moral de los valores cristianos (Moral der christlichen Werthbegriffe), especifica que «los evangelios nos presentan los mismos tipos fisiológicos que describen las novelas de Dostoievski». ${ }^{69}$ Esta semejanza, de todos modos, no se ha de reconducir a una posible influencia por parte de Brandes en Nietzsche, a la hora de escribir obras como El caso Wagner o El Anticristo - influencia que Ch. Andler destaca, según nuestro juicio de manera equivocada, en su estudio Nietzsche et Dostoievski ${ }^{70}$-, sino que, mas bien, ha de suponerse todo lo contrario. Según refieren G. Colli y M. Montinari en su relato de la vida del filósofo alemán, ${ }^{71}$ El caso Wagner fue escrito por Nietzsche a inicios del año 1888 y llevado a la imprenta en el verano del mismo año, es decir, dos meses antes de la breve correspondencia con Brandes acerca de Dostoievski. Además, como nos informa el mismo filósofo en la carta del 14 de octubre de 1888 a Gast, ${ }^{72}$ una copia de El caso Wagner pasó por las manos de Brandes, el cual la envió a su vez al escritor sueco Strindberg. En este sentido, habría que excluir una posible influencia por parte de Brandes en la identificación nietzscheana de los protagonistas de las novelas dostoievskianas con los tipos fisiológicos, de los que los Evangelios están llenos.

Si negamos, entonces, una directa influencia del estudioso danés en $E l$ Anticristo nietzscheano, ¿cómo explicar la atribución de la idiotez a Jesús por parte del filósofo alemán, sino como una prueba patente de la lectura de $E l$ idiota dostoievskiano? O ¿se creerá, al contrario, que el instinto de afinidad y de parentesco fuese tan hondo, hasta llevar a los dos pensadores a la misma interpretación de la figura central de los Evangelios?

La respuesta a estas dos preguntas es, en realidad, más complicada de lo que se pueda pensar. Justamente por el hecho de que Nietzsche no dejó ninguna información acerca de una lectura directa de la obra dostoievskiana y por la ausencia completa de las novelas del autor ruso en la biblioteca del filósofo

69 F. Nietzsche, El caso Wagner, «Epílogo», en F. Nietzsche, Obras completas, IV, tr. P. Simon. Buenos Aires: Prestigio, 1970, p. 51.

70 Ch. Andler, op. cit., pp. 13-14: «La novela El idiota ha sugerido a Nietzsche una nueva imagen de la primera comunidad cristiana. Jesús tuvo que ser una especie de príncipe Myskin con traje oriental. El "reino de Dios", donde se sentía feliz de vivir, era un ambiente consituido hasta tal punto por publicanos y chicas, artesanos groseros y caminos poco seguros, que, incluso entre los doce apóstoles, se pudo encontrar un traidor venial. A decir verdad, fue el danés Georg Brandes, quien sugerió a Nietzsche esta comparación». Andler cita a continuación la mencionada carta de Brandes a Nietzsche de 23 de noviembre de 1888.

71 Cf. G. Colli y M. Montinari, op. cit., pp. 173 s.

72 Cf. F. Nietzsche, Briefwechsel, III, 5, op. cit., p. 451. 
alemán, los críticos no siempre incluyen El idiota entre las novelas leídas por Nietzsche.

La mayoría de las interpretaciones de los críticos, que han expresado su opinión acerca de este tema, suelen basarse sobre el siguiente fragmento póstumo de la primavera de 1888, titulado Jesús: Dostoievski:

Conozco solamente a un psicólogo que haya vivido en el mundo en el que el cristianismo es posible, en el que en todo momento puede surgir un Cristo...Y ése es Dostoievski. Él ha adivinado a Cristo: - e instintivamente ha quedado preservado ante todo de representarse a este tipo con la vulgaridad de Renan... ¡Y en París se cree que Renan sufre de excesivas finesses [finuras, refinamientos]!... ¿Pero se puede fallar de peor manera que haciendo de Cristo, que fue un idiota, un genio? ¿Que sacando mentirosamente de Cristo, que representa la antítesis de un sentimiento heroico, un héroe? $?^{73}$

En la redacción definitiva de El Anticristo, Nietzsche no cambia de opinión y vuelve a criticar la utilización por parte de Renan de los dos conceptos de genio y de héroe para explicar al tipo Jesús. Al contrario, hay una única palabra que ayuda a comprender la psicología del Redentor -y nótese que aquí Nietzsche habla con el rigor del fisiólogo (Mit der Strenge des Physiologen)-, la palabra idiota:

El señor Renan, ese bufón in psichologicis [en cuestiones psicológicas], ha aportado a su aclaración del tipo Jesús los dos conceptos más inapropiados que para esto puede haber: el concepto genio y el concepto héroe («héros»). Pero si hay algo no-evangélico es el concepto héroe. Cabalmente la antítesis de toda pugna, de todo sentirse-a-sí-mismo-en-lucha se ha vuelto aquí instinto: la incapacidad de oponer resistencia se convierte aquí en una moral («no resistas al mal», la frase más honda de los evangelios, su clave, en cierto sentido), la bienaventuranza en la paz, en la afabilidad en el no-poder-ser-enemigo. ¿Qué significa la «buena nueva»? La vida verdadera, la vida eterna está encontrada - no se la promete, está ahí, está dentro de vosotros: como vida en el amor, en el amor sin sustracción ni exclusión, sin distancia. Todo hombre es hijo de Dios -Jesús no reclama nada para sí solo- en cuanto hijo de Dios todo hombre es idéntico al otro... ¡Hacer de Jesús un héroe! ¡Y qué malentendido es sobre todo la palabra «genio»! Nada de nuestro concepto, de nuestro concepto cultural de «espíritu» tiene sentido alguno en el mundo en que Jesús vive. Dicho con el rigor del fisiólogo, aquí estaría en su lugar más bien, una palabra completamente distinta: la palabra idiota. ${ }^{74}$

73 F. Nietzsche, Fragmentos póstumos (1885-1889), primavera de 1888, 15 [9], op. cit., p. 626.

74 F. Nietzsche, El anticristo, 29, tr. A. Sánchez Pascual. Madrid: Alianza, 2006, pp. 64 s. 
La descripción del mundo enfermo de los Evangelios como «un mundo que se diría salido de una novela rusa» ${ }^{75}$ junto a la referencia directa en el mismo párrafo al escritor ruso - «habría que lamentar que en la cercanía de ese interesantísimo décadent no haya vivido un Dostoievski, quiero decir, alguien que supiera sentir precisamente el atractivo conmovedor de semejante mezcla de sublimidad, enfermedad e infantilismo» ${ }^{76}$-, ha llevado a muchos estudios de la relación entre Nietzsche y Dostoievski a ver en los pasos mencionados una clara alusión a la lectura por parte del filósofo alemán de la obra El idiota.

En este sentido, C. A. Miller indica como posible (perhaps) dicha lectura ${ }^{77}$ -y de la misma opinión parece ser W. Gesemann ${ }^{78}-$, pero, en otro estudio posterior, el mismo Miller especifica que la comparación entre el mundo enfermo de los Evangelios y aquello como salido de una novela rusa ( $\$ 31$ de El Anticristo) podría ser más bien una alusión plausible a la teoría de la armonía eterna de Kirillov, uno de los personajes de Los demonios $^{79} \mathrm{Al}$ contrario, la mayoría de los estudiosos -entre los más destacados, Ch. Andler, ${ }^{80} \mathrm{H}$. de Lubac, ${ }^{81} \mathrm{~A}$. U. Sommer ${ }^{82}$ D. M. Hoffmann ${ }^{83}$ y G. Pacini ${ }^{84}$ - han opinado que las muchas similitudes entre la caracterización del príncipe Myshkin, el idiota dostoievskiano, y la descripción nietzscheana del tipo del Redentor es, ya de por sí, una prueba bastante evidente de una influencia directa del escritor ruso sobre el filósofo alemán. Evitando adentrarnos en las varias facetas de esta complicada cuestión, preferimos limitarnos a subrayar cuanto razonable e indudable nos parece la afirmación de Giorgio Colli, según el cual no cabe duda de que el término idiota utilizado por Nietzsche en El Anticristo y en los fragmentos póstumos de este periodo, haya de entenderse aproximadamente en la misma manera en que Dostoievski lo utilizó en su novela El idiota, refiriéndose al príncipe Myshkin. ${ }^{85}$

De todos modos, no ha de excluirse que Nietzsche llegara a conocer la obra dostoievskiana El idiota a través de un estudio de E. M. De Vogüé sobre la no-

75 Ibid. 31, p. 67.

76 Ibid.

77 Cf. C. A. Miller, op. cit., p. 203.

78 W. Gesemann, op. cit., pp. 142 ss.

79 C. A. Miller, «The Nihilist as Tempter-Redeemer: Dostoevsky's "Man-God" in Nietzsche's Notebooks», Nietzsche Studien. Internationales Jahrbuch für die Nietzsche Forschung , IV (1975), p. 180.

80 Cf. Ch. Andler, op. cit., p. 3.

81 Cf. Henri de Lubac, Le drame de l'humanisme athée. Paris: Spes, 1945, p. 290.

82 Cf. Andreas Urs Sommer, Friedrich Nietzsches «Der Antichrist». Ein philosophischhistorischer Kommentar. Basel: Schwabe, 2000, p. 317.

83 D. M. Hoffmann, «Idiot», en H. Ottmann (ed.), Nietzsche Handbuch. Leben - Werk - Wirkung. Weimar: Metzler, 2000, p. 256.

84 Pacini G., Nietzsche lettore dei grandi russi. Roma: Armando, 2001, pp. 30 ss.

85 Cf. G. Colli, Note, 8, en F. Nietzsche, L'anticristo. Milano: Adelphi, 2000, p. 108. 
vela rusa. En este estudio, titulado Le roman russe y publicado por la editorial parisiense Plon en $1886^{86}$, de Vogüé dedica un capítulo entero a Dostoievski, en el que resume brevemente los acontecimientos principales de la vidas del escritor ruso y analiza algunas de sus novelas. El critico francés define a Dostoievski de diferentes maneras -un psicólogo, un filósofo, un metafísico y un realista-y muestra patentemente toda su preferencia por tres obras que, según su opinión, revelarían de mejor manera los aspectos diferentes de su talento: Pobres gentes (Bednye ljudi), Memorias de una casa muerta y Crimen y castigo. Al contrario, El idiota, Los demonios y sobre todo Los hermanos Karamazov son obras criticadas por su estensión intolerable y su dialéctica barroca.

Prescindiendo del juicio crítico de de Voguié, lo que aquí más nos interesa es la posibilidad de que Nietzsche llegara a conocer El idiota a través de la obra del crítico francés ${ }^{87}$, aunque no disponemos de ninguna prueba que atestigue una posible lectura por parte del filósofo de Le roman russe. En la biblioteca personal de Nietzsche no ha sido encontrada ninguna obra de de Vogüé, ni tampoco en el epistolario se hace referencia al crítico francés. Solamente en el Nachlss nietzscheano es posible encontar el siguiente pequeño fragmento de diciembre de 1888 - comienzo de enero de 1889 , en el que el filósofo hace referencia al crítico francés:

Petits faits vrais [pequeño hechos verdaderos]

Fromentin

De Vogüé. ${ }^{88}$

Este fragmento, que representaría un esquema para un añadido proyectado para Ecce homo, por una parte atestigua el conocimiento del crítico francés por parte de Nietzsche, pero por otra parte es insuficiente como para comprobar una posible lectura de Le roman russe. De todos modos, cabe la posibilidad de que el filósofo leyera algunos de los artículos que De Vogüé publicó en la Revue des Deux Mondes entre el 15 de octubre de 1883 y el 15 de mayo de 1886, artículos que, revisados, constituyeron los diferentes capítulos de Le roman russe.

La influencia dostoievskiana en El Anticristo nietzscheano no se limitaría, de todos modos, a El idiota, sino que se percibe también en la lectura de otra obra del escritor ruso, Los demonios, que tanto interés tuvo que suscitar en el filósofo, si éste dedicó más de diez páginas (formato in folio) de sus cuadernos a

86 E. M. De Vogüé, Le roman russe. Paris: Plon, 1886.

87 Aunque de Vogüé dedique solamente tres páginas a El idiota, las informaciones acerca de esta novela son suficientes como para justificar la mencionada asociación nietzscheana de $E l$ anticristo entre Cristo y la "mezcla de sublimidad, enfermedad e infantilismo".

88 F. Nietzsche, Fragmentos póstumos (1885-1889), diciembre de 1888 - comienzo de enero de 1889, 25 [4], op. cit., p. 774. 
la trascripción de fragmentos de esta novela, ${ }^{89}$ que él mismo leyó en la traducción francesa de V. Derély. ${ }^{90}$ En este sentido, no se puede negar, por ejemplo, que la crítica al concepto cristiano de Dios (El Anticristo, §\$16-19) sea indudablemente influenciada por el discurso entre Shatov y Stavrogin (II, 1, 7), dos de los demonios de la novela dostoievskiana.

\section{CONCLUSIÓN}

Como revelan las obras, las cartas y los fragmentos póstumos del último periodo, el descubrimiento de Dostoievski, aunque tardío, fue indudablemente apreciado por Nietzsche, que vio en el escritor ruso un espíritu afín y un alma angustiada por las mismas cuestiones y problemáticas. En las novelas dostoievskianas, el filósofo alemán pudo encontrar un material psicológico muy útil para confirmar sus análisis sobre el ressentiment, la décadence, el nihilismo y las demás temáticas, que seguían despertando su curiosidad y su interés. Ambos pensadores habían recorrido dos caminos similares y cuando en una tienda de Niza estos dos caminos se cruzaron de una forma absolutamente casual y fortuita, Nietzsche no pudo sino reconocer enseguida la extrema afinidad de las dos trayectorias espirituales.

PAOLO STELLINO. Universidad de Valencia. Dpto. de Filosofía del Derecho, Moral y Política.

Publicaciones recientes:

P. Stellino, «L'illusione del tempo: il tema dell'eternità in Borges e Nietzsche», Nae, XIV (2006), pp. 39-42.

P. Stellino, «Jesus als "Idiot”: Ein Vergleich zwischen Nietzsches Der Antichrist und Dostojewskijs Der Idiot», Nietzscheforschung, XIV (2007), pp. 203-210.

Línea de investigación:

Becario F.P.U. y doctorando, investiga actualmente -bajo la dirección del Prof. J. Conill-la relación entre Nietzsche y Dostoievski, con particular atención al problema de la fundamentación de la moral en ambos autores.

Dirección postal:

Paolo Stellino. Secció Deptal. Filosofia Moral, Facultat de Filosofia y Ciències de l’Educació, Av. Blasco Ibáñez, 30, 46010 Valencia.

Dirección electrónica: paolo.stellino@uv.es

89 Cfr. F. Nietzsche, Fragmentos póstumos (1885-1889), Noviembre de 1887-Marzo de $1888,11[331 ; 333-341 ; 344-351 ; 379-380]$.

90 F. Dostoïevski, Les Possédés, op. cit. 
